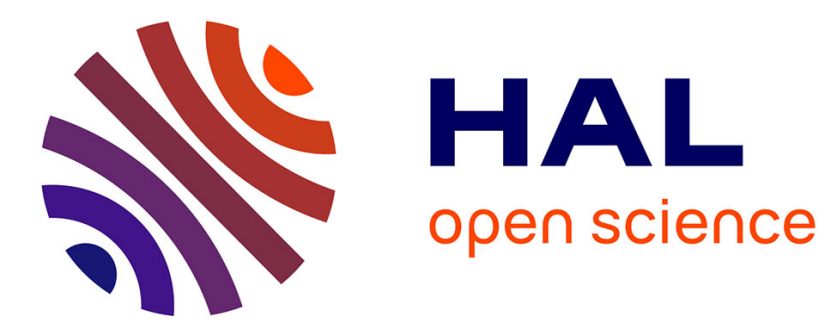

\title{
All practices are shared, but some more than others: Sharedness of social practices and time-use in food consumption
}

\author{
Marie Plessz, Stefan Wahlen
}

\section{- To cite this version:}

Marie Plessz, Stefan Wahlen. All practices are shared, but some more than others: Sharedness of social practices and time-use in food consumption. Journal of Consumer Culture, 2022, 22 (1), pp.143-163. $10.1177 / 1469540520907146$. hal-02490082

\section{HAL Id: hal-02490082 \\ https://hal.science/hal-02490082}

Submitted on 24 Feb 2020

HAL is a multi-disciplinary open access archive for the deposit and dissemination of scientific research documents, whether they are published or not. The documents may come from teaching and research institutions in France or abroad, or from public or private research centers.
L'archive ouverte pluridisciplinaire HAL, est destinée au dépôt et à la diffusion de documents scientifiques de niveau recherche, publiés ou non, émanant des établissements d'enseignement et de recherche français ou étrangers, des laboratoires publics ou privés.

$$
\text { Copyright }
$$




\title{
All practices are shared, but some more than others. Sharedness of social practices and time-use in food consumption
}

\author{
Marie Plessz \\ Centre Maurice Halbwachs (CMH), EHESS, ENS, CNRS, PSL, \\ INRAE, France \\ Stefan Wahlen \\ University of Giessen, Germany \\ Corresponding author: \\ Stefan Wahlen, University of Giessen, Senckenbergstraße 3, 35390 Gießen, Germany. \\ Email: stefan.wahlen@uni-giessen.de
}

Published in Journal of consumer culture

Online first 18 february 2020, DOI : $\underline{10.1177 / 1469540520907146}$

\section{Accepted version}

\begin{abstract}
Even though we spend less and less time cooking and eating, food consumption remains a corner stone of the temporal organisation of everyday life. This paper is interested in how and to which extent food practices can be described as shared. We situate our investigation at the confluence of practice theories and the empirical analysis of time-use surveys. While qualitative research highlights the interrelations between many activities and agents necessary to consume food, quantitative data, such as time-use surveys, underscore the shared temporality of eating. We ask whether practices are shared beyond being socially recognized and mutually understandable forms of actions. Accordingly, we are interested in how some practices might be described as more shared than others, or shared in different ways? We identify three characteristics of sharedness: participation, commitment and temporal concentration. The latter is a key indicator of dispersed collective activity, inasmuch as participants engage in the practice in similar ways even without coordinating explicitly around it. We measure and compare the characteristics of sharedness by analysing the Dutch time-use survey $2011(\mathrm{~N}=2,005)$. Such an analysis offers empirical evidence for our characterisation of sharedness by mapping five food-related practices (eating a meal, snacking, cooking, shopping, cleaning) onto five dimensions of temporality (duration, sequence, periodicity, synchronisation, tempo). The characteristics of sharedness afford a systematic framework to analyse culture in dispersed collective activity. Our analysis also provides novel vistas to reflect upon power in shared practices by investigating their temporal concentration.
\end{abstract}

Keywords: Time-use; temporality; Netherlands; practice theory; collective activity; snacking; eating; shopping; cooking. 


\section{Introduction}

Consumption and time use are inextricably linked. From a sociological perspective, both can be considered as an aspect of a vast range of social activities. Recent research on consumption, inspired by theories of practices, highlights that most practices involve consumption at some point, hence consumption is a step in the process of many practices rather than a practice in itself (Warde, 2005). Similarly, the sociology of time spans a variety of topics, from organisations to leisure, paid and unpaid work, or family relations (e.g. Gershuny, 2003). The temporal organisation of daily life (Zerubavel, 1979; Fine, 1996; Abbott, 2001) is also investigated from the standpoint of theories of practices (Blue, 2017; Southerton, 2013). This paper interrogates the relationship between praxeological thinking and time-use analysis by examining how time-use data can empirically assess whether and how practices are shared in a society—what we shall call 'sharedness'.

Arguably, every practice is shared in the sense that it is social. Some practices are shared because people perform it together. The sharedness of food practices, our object of study, is interesting for two reasons. First, even if people often gather around a meal, eating food can be done alone. If food consumption is collective, it is more so in the sense of 'dispersed collective activity' (Welch and Yates, 2018) than as organised collective performance. Second, food consumption is more complex than a single practice, as it consists of several distinct yet connected practices. We consider all the activities that are performed in order to consume food (e.g. acquisition, storing, preparing, eating, cleaning), emphasising the compound practice of eating (Warde, 2013, 2016).

Some researchers have already provided significant theoretical and empirical insight into the junction of practice theories and time use studies, mostly with qualitative data (Southerton, 2006; Mylan and Southerton, 2018; Warde and Yates, 2017). Time-use surveys (TUSs) assist in operationalising the praxeological notion of 'shared practice'. The paper builds on the literature on time use, practice theories, and consumption in order to decompose 'sharedness' into three measurable characteristics; it then uses these characteristics to compare food consumption practices (cooking, cleaning, shopping, eating a meal, eating a snack) in the Dutch TUS 2011. In the end, we argue that quantitative surveys, such as TUSs, allow to describe and compare how individual, apparently independent performances aggregate into shared practices. Sharedness and its characteristics might indeed serve as a praxeological way to compare practices across time and space. We also strengthen and systematize the connections between theories of practices and the analysis of time-use, by focusing on socially recognizable and sociologically well-described practices rather than on broad aggregate categories of activities such as leisure or (un)paid work (as in Gershuny, 2000; Tienoven et al., 2017). Last, we open up perspectives on how to address power and culture when examining practices. 


\section{Theoretical background}

Shared practices matter sociologically because they constitute the culture of a given population (Shove et al, 2012). Barnes' (2001) example of a cavalry charge indicates that shared practices also yield power. Shared practices, however, should not be reduced to those performed by several people together: Barnes argues that practices performed individually raise the same questions and should be analysed the same way as collective practices. Welch and Yates (2018) seem to share this view, when they describe three forms of collective action: the bureaucratic organisation, the grouping (such as a social movement), and the 'dispersed collective action' which is not explicitly coordinated. This paper deals precisely with practices that may constitute dispersed collective action, that are shared without necessarily being performed togetheri. Our point is that such practices may be shared to a different extent, or in different ways. We decompose sharedness into three characteristics: participation, commitment, and (temporal) concentration.

\section{Sharedness as participation, commitment, and concentration}

Participation refers to the number of practitioners a practice has recruited, as when we say that a practice is 'widely shared'. Practices vary tremendously on this respect and the same practice may vary over time. Among the practices reviewed by Shove, Pantzar and Watson (2012), some are widespread (cooking), some are much rarer (mountain biking), some became widely shared before nearly disappearing (hula-hooping). Participation is interesting because it is a notion familiar to time-use survey analysts, who often report participation rates along with duration (for example Gershuny, 2000). Researchers using theories of practice also often report participation rates to indicate how widely a practice has disseminated (food-related examples can be found in Truninger, 2011; Twine, 2018).

A second characteristic of sharedness is commitment, which refers to resources that practitioners devote to the practice, amongst which, notably, their time. Cooking with the Bimby, a cooking device assisting in the preparation of food, provides a good case (Truninger, 2011). The salesperson interviewed by Truninger emphasized that the practice of cooking with the Bimby required a high degree of commitment: because the device is very expensive, the practice only makes sense if it is performed very often, to prepare a large variety of foods. On the contrary, some practices do not take much time or resources from those who perform it: participants, no matter how many, are not very committed to it. The notion of degree of commitment to a practice has mostly been used at the individual level (Plessz and Gojard, 2015; Southerton, 2006), in order to capture how much each participant valued the practice and gave it priority in her daily schedule. Here we recast it as characteristic of the practice. The fact that practitioners show a high degree of commitment indicates that the practice is shared 'deeply', in the sense that its practitioners are strongly dedicated to it. This matters sociologically because a practice that succeeds at capturing large amounts of time from a category of people may become part social 
identities. Pred (1981) argued that such practices form 'dominant projects' that belong to the institutional role performed by such category of people.

A third characteristic of sharedness is concentration. Concentration refers to the degree of similarity across performances of the same practice. It results from and is indicative of the coordination and regulation of performances. However, concentration shows even when coordination is not visible in the course of performances, hence 'solo practices' such as administering acupuncture may be as concentrated as the 'collective practice' of riding in formation (Barnes 2001:34). In order to make concentration an empirically relevant characteristic of shared practices, we turn to Welch and Yates (2018) and their notion of dispersed collective activity. Such activity 'takes its socio-environmental significance from the concentrations of the material, spatial and temporal in performing practices' (Welch and Yates, 2018: 299, emphasis added). Welch and Yates mention 'feeding a family' as examples of such activity and indeed, it is easy to draw parallels between this view of dispersed collective activity and a practice such as eating a meal. Meals are concentrated at culturally specific times of the day (Callejo and Díaz-Méndez, 2014) and in specific places (e.g. at home, at the dinner table, or in front of the television), even when people eat alone (Yates and Warde, 2017). After heated debate over the destructuration of eating, empirical evidence has accumulated showing that meal synchronisation across the day has remained stable over the last decades (Cheng et al., 2007; Holm et al., 2016; Lhuissier et al., 2013). Hence, eating a meal is not only widely shared, it is also performed in specific places and times of the day. Temporal concentration is of special interest but requires further elaboration.

\section{Temporality}

Temporality refers to our experience and perception of time. A classic example is conceiving of time as the sequence of past, present, and future, as opposed to cyclical time (for example, the day, the seasons). Temporality builds on time-use research and fits well with our praxeological perspective. Practices are spatially and temporally unfolding nexuses (Schatzki, 1996, 2001). Through practices we experience time, as when time flies, or when we take, spend, or waste time (Holmes, 2015; Shove et al., 2009). Zerubavel (1979) pointed out that shared temporal patterns (practices performed in similar ways from the temporal point of view) contribute to the formation of collective identities. Hence, the sharedness of practices contributes to making someone feel Dutch (having lunch around 12:30 and diner around 18:10), French (lunch around 12:30 and diner around 20:00), or Spanish (lunch around 14:20 and diner around 21:10, Callejo and Díaz-Méndez, 2014; Saint Pol (de) and Ricroch, 2012). Going further, however, requires to consider temporality in a more systematic way.

A number of sociological essays have addressed the temporal organisation of practices, including those of Zerubavel (1979), Fine (1996), or Southerton (2006). Despite their different theoretical points of departure, all move away from measuring how much time people spend towards examining how they 
organise activities - and their time. Such an understanding is not reduced to duration or timing. Southerton (2006) used Fine's typology (1996: 55):

Periodicity refers to the rhythm of the activity; tempo, to its rate or speed; timing to the synchronization or mutual adaptation of activities; duration, to the length of an activity; and sequence to the ordering of events.

According to Southerton (2006: 452):

The advantage of considering how social practices map onto Fine's five dimensions of time is that it allows for the analysis of several factors: the interrelationship between different practices; how practices are sequenced to produce the temporal rhythms of daily life; and, when taken together with varieties of social constraints, the nuances of temporal experience.

Referring to a slightly different typology of temporality, Tienoven (2018: 16) argues that the routines of duration, timing, tempo, and sequence may combine:

\section{Daily activities can either be part of a single routine or a combination of two or more routines. One might, for example, go sporting every Tuesday and Thursday (i.e. routine of tempo), always after work (i.e. routine of sequence) and always for an hour (i.e. routine of duration), but since the end of the working day varies, not always at the same time.}

A growing body of research adopts a praxeological perspective on time use (Blue, 2017; Tienoven et al., 2017), but most studies focus on a single dimension of time. Plessz and Étilé (2019) have studied the decline in cooking duration in France and the US from 1985 to 2010. Southerton et al. (2012) also focused on duration when comparing different modes of engagement in the practice of reading. Yates and Warde (2017) took a more encompassing route when examining timings and durations of meals and snacks in Britain (see also Warde and Yates, 2017). Time-use research has long focused on duration (how long) and timing (at what time), but ever more researchers have tried to address the temporal organisation of the day, probably in relation with the development of sequence analysis. For example, De Saint Pol (2005) focused on the sequences of activities around dinners in France. Tienoven et al. (2017) studied the stability of practices from day to day, focusing on timings (a practice is stable if it happens at the same hour every day).

We decided to analyse the concentration of practices on each of the five temporal dimensions used by Fine (1996) and Southerton (2006). We assume that different practices may be concentrated along different temporal dimensions. Some may be concentrated in terms of synchronisation (as seems to be the case with meals), but others may form very specific and widely shared sequences with other practices. In the end however, we will try to summarise temporal concentration as a single index to be compared with the levels of participation and commitment of the respective practice. The three characteristics of sharedness, we argue, capture how and to what extent practices such as eating a meal or grocery shopping are shared in a society. Our analyses purposively ignored the coordination of 
performances across performers, typically synchronicity inside the household (see Brannen et al., 2013), assuming that concentration across unrelated performers was a more stringent definition of sharedness.

\section{Data and methods}

We now explain how we translated participation, commitment and temporal concentration into the language of variables and statistical measurements adapted to the Dutch time-use survey. Measuring participation and commitment is quite straightforward but temporal dimensions and their concentration are less often studied.

\section{Survey and sample}

We use the Dutch Time-use survey because Dutch society does not differ much from other continental European countries in terms of time use (Cloïn, 2012), and because the survey collects one-week-long diaries, which allow to identify regularities that extend beyond one day (most TUSs cover one or two days). The survey is part of the multinational time-use survey (MTUS) supported by the Center for timeuse research in Oxford, and since 2011, it is further harmonised within the Harmonised European Time Use Survey (HETUS) supported by Eurostat (Centraal Bureau voor de Statistiek, 2012b). The Dutch TUS 2011 relies on a stratified random sample of Dutch residents aged over 9 years old $(\mathrm{N}=2,005)$. The sample is drawn from municipal registries. The refusal rate was $50 \%$, and another $10 \%$ of the initial sample did not complete the diary, which is not uncommon for a TUS. We used the whole sample of the Dutch TUS 2011, including children. The TUS was collected between March 2011 and March 2012, and were the most recent data available at the time of writing. After a short questionnaire describing the household, every household member over 9 years old received a paper diary covering seven days, divided into 10-minute timeslots. Respondents were asked to report their activities in their own words. Trained coders coded the verbatims into a detailed classification of activities such as code 3112 (preparing a meal) or code 3113 (warming-up a pre-prepared meal) (Centraal Bureau voor de Statistiek, 2012a). In this paper, we use the word 'activity' to refer to such codes.

\section{Measuring participation, commitment and concentration with time-use data}

Most time-use analyses group detailed activities into larger groups, typically into paid work, unpaid work, leisure, and personal time (Gershuny, 2000). Instead, we grouped activities in a sociologically and praxeologically meaningful way, relying on the literature in sociology of food and eating. We call such groups 'practices' (for further elaboration see Plessz and Étilé, 2019: 96), For instance, praxeological thinking and the sociology of eating emphasise empirical and theoretical reasons to differentiate eating a meal from eating a snack (Lhuissier et al., 2013; Twine, 2015; Warde and Yates, 2017). We were able to make this distinction: 'eating a meal' (labelled 'meal') refers to activity codes 
0210 to 0219 , whereas eating a 'snack' groups codes 0220 to 0229 . Under the label 'cooking', we grouped all kinds of food preparation, from cooking a meal to heating a ready-prepared dish, including preserving food (codes $3110,3112,3113,3119,3120,3140,3190$ ). Grocery shopping corresponds to codes 3611 and 3610. We grouped setting the table (code 3111) and clearing the table, doing the dishes and loading/unloading the dishwasher (code 3130) under the label 'cleaning'. Grouping them made the statistical analysis more robust without compromising sociological interpretation.

In order to measure participation and commitment, we referred to indicators that are widely used in time-use analysis. Participation is captured by the participation rate, that is, the percentage of people who performed the practice at least once during a given period. We computed it for the survey week, but also for Mondays and Saturdays. A first indicator of commitment to the practice is the conditional duration: it is the total time devoted to the practice for those who have performed at least once. We computed it over the week. We also computed the number of episodes that respondents reported over the survey week.

The measures for the last characteristic of sharedness, concentration, are a bit more complex. We built measures of concentration for each dimension of temporality from the diary data (see Appendix Table A1 for an overview). Since periodicity refers to how often people perform a practice, we counted the number of events reported on a given day. For synchronisation, we were interested in whether survey respondents reported the practice at the same time of the day, so we computed the participation rate for each 10-minute slot of the day (the percentage of respondents reporting the practice from 6:00 am to 6:10, etc.). Duration refers to how much time practitioners devote to the practice: to measure it we aggregate the duration of all episodes on a given day (this is the same as the conditional duration over a day, the duration for respondents who have participated on that day). Tempo is captured by the duration of one episode. Sequence was treated differently. First, we merged activities not related to food into their parent category (e.g. personal care, using transport, paid work). We left the food-related practices as described above. For each food-related practice, we computed the frequency at which different practices or activity categories were recorded just before and just after each episode of the practice of interest. We report the most frequent activity just before (and just after) each food related episode, over the week. This can be watching TV, or cookingii.

In order to describe the sharedness of practices, we needed a way to measure temporal concentration on each dimension. Concentration (or its opposite, dispersion) is a statistical concept. For example, variance measures dispersion. Dispersion is usually measured around a 'position parameter', such as the mean. Other dispersion parameters exist that are sometimes more relevant than variance, especially when comparing dispersion. We adapted the choice of the position and dispersion parameters to the statistical properties of each temporal dimension (see table A1 in the Appendix). Since some indicators capture statistical dispersion while others capture concentration, highest temporal concentration is defined in the last column. 
For periodicity and duration, the position was the mean (mean duration, mean number of episodes per day) and the dispersion was the coefficient of variation, which is the variance divided by the mean (allowing to compare dispersion across variables with different mean values). For synchronisation, the position is indicated by the mode, that is, the starting time of the time-slot where participation to this practice was maximum (for example, 17:40). The parameter for concentration that we chose was relative participation during this time-slot: participation rate at that time, among those who had participated at least once on the day considered. For tempo, the position is the median duration while the dispersion parameter is the interdecile range, which is the interval between the $10 \%$ shortest and $10 \%$ longest episodes, across the week. For sequence, we reported the most frequent practice (or category of activities as defined above) just before, or just after, the practice considered, and the $\%$ of such episodes following (or preceding) it. The temporality of eating practices is cyclical but the relevant timeframe may vary across practices. The one-week long diary of the Dutch time-use survey allows us to measure temporal concentration over each day of the week or over the week. For periodicity, duration and synchronisation, our measures were robust enough to be computed over a single day, so we reported results for Mondays and Saturdays (in the Appendix). For tempo and sequence, we made the computations over the whole week. Last, we computed an index of concentration using the above variables. Each practice receives one point for each dimension on which it has the highest. We subtract one point for each dimension on which it has the lowest concentration.

\section{Results}

\section{Participation and commitment}

Participation rates of food-related practices are quite high over the week, reflecting the fact that we are discussing practices that are widespread and frequently repeated (see Table 1). The participation rate for eating the meal is 100\% (99.996\% precisely, around 97\% per day). One might argue that everyone has to eat, but eating a snack, another practice that involves food ingestion, has a much lower participation rate $(28 \%$ over the week, around $7 \%$ on a given day). The very high participation to eating a meal is rather a characteristic of that social practice which makes it different from eating a snack. Participation rates for cooking $(75 \%)$ and cleaning $(85 \%)$ reflect the social organisation of these practices. Eating a meal cannot be delegated, while cooking or cleaning can, pointing towards the social household dynamics with regard to food practices. In the Netherlands as in many countries, women often do most of the cooking and cleaning for the whole household, male respondents and children participate less (Tai and Treas, 2013). People may also eat meals in restaurants, at friends' places or may have a ready meal at home.

Commitment, understood as the time devoted to the practice by people who practiced at least once over the survey week, ranks practices in a somewhat similar way: participants to meals (nearly the whole 
sample) devoted nearly 9 hours to them while those who took at least one snack spent one hour on that practice. While cooking and shopping had similar participation rates over the week, commitment was higher for cooking (3:21 hours vs 2:38). The average number of episodes per week gives a complementary view of commitment. People cook about seven times a week, clean nearly five times a week and shop less than three times.

Shopping stands out as the only practice for which weekly participation and commitment indicators diverge. People perform shopping less than three times per week on average, contrasting with over 16 meals. Only snacking is performed less often. Yet, these three shopping episodes capture 2:38 hours per week, and $85 \%$ of the sample has participated in shopping, which is more than cleaning (five episodes per week and $75 \%$ participants). Daily participation on Mondays and Saturdays suggests that shopping varies greatly from day to day. They display participation rates over the day for each practice, on Monday and Saturday. Participation rates to shopping exhibit a different pattern on Saturday: the line reaches a plateau that lasts from 11:00 to around 15:00. It is therefore necessary to examine temporal concentration for each practice in a systematic way.

Table 1: Participation and commitment to food consumption practices in the Dutch Time-use survey 2011

\begin{tabular}{llrrrrr}
\hline & & Cooking & Cleaning* & Meal & Shopping & Snack \\
\hline Average total time respondents spent per week & $2: 48$ & $1: 26$ & $8: 57$ & $2: 14$ & $0: 11$ \\
\multirow{2}{*}{ Participation } & & & & & \\
& & & & & & \\
& \% of respondents participating per week & $84 \%$ & $75 \%$ & $100 \%$ & $85 \%$ & $28 \%$ \\
& \% of respondents participating on Monday & $59 \%$ & $45 \%$ & $98 \%$ & $30 \%$ & $7 \%$ \\
& \% of respondents participating on Saturday & $51 \%$ & $40 \%$ & $97 \%$ & $50 \%$ & $8 \%$ \\
& & & & & & \\
Commitment & & $3: 21$ & $1: 54$ & $8: 57$ & $2: 38$ & $0: 42$ \\
& Total time participants spent each week & 7.1 & 4.9 & 16.5 & 2.8 & 0.6 \\
\hline
\end{tabular}

\footnotetext{
* Cleaning includes setting the table, clearing the table, doing the dishes, fill or empty the dishwasher. Source: Dutch time-use survey 2011 (Centraal Bureau voor de Statistiek, 2012b), full sample (N=2005). Reading note: In average, respondents have spent 2 hours 48 minutes cooking during the survey week. The percentage of respondents who cooked at least once during the week was $84 \%$, with $59 \%$ having cooked on Monday and $51 \%$ on Saturday. Among those who had cooked that week, the average time spent cooking was 3 hours 21 minutes. The average number of cooking episodes among all respondents was 7.1.
}

\section{Temporal concentration}

The temporal concentration of food-related practices varies greatly, both across practice and across temporal dimension. Results appear in Table 2 below and in a more detailed form in the Appendix (Table A2). Eating a meal is the practice with the strongest temporal concentration, suggesting that meals follow very similar temporalities. Meals have the highest concentration on periodicity and duration. This 
means that the number of episodes and the total time spent eating over a day are very similar across respondents. They also have the highest synchronisation: at 18:10, a third of the respondents are eating. Meal tempo varies more: while $10 \%$ of the meals last 10 minutes or less, $10 \%$ last over 50 minutes. Eating snacks contrasts vividly with meals: snacks have the lowest concentration on periodicity, synchronisation and sequence. Saturday snacks have also the strongest variation in duration.

It is interesting to compare cooking and cleaning because these practices exhibit similar levels of participation and commitment. As regards concentration, they contrast not only on how much but also how they are concentrated. This illustrates how important it is to analyse temporal concentration in detail. Cleaning has the highest concentration on tempo, with $90 \%$ of cleaning episodes lasting between 10 and 30 minutes. But in terms of periodicity, synchronisation and duration, cleaning is less concentrated than cooking - it varies more across respondents. As regards sequence, cooking and cleaning exhibit contrasting patterns. Cooking forms the most concentrated (that is, similar) sequences with what comes after it because nearly half of cooking episodes are followed by eating a meal. But the sequence that precedes cooking is very diverse, with the most frequent activity, personal care, declared only before $9 \%$ of cooking episodes. Personal care itself groups various practices such as dressing or washing. Cleaning forms its most frequent sequences with meals, either cleaning-then-eating or eatingthen-cleaning. However, the sequence where cleaning follows meal is much more frequent $(57 \%$ of episodes) than the other way around (13\%). There are probably sequences of cleaning-eating-cleaning since in our analysis cleaning practices include setting the table, clearing the table and doing the dishes. Shopping illustrates the fact that the daily or weekly time-frame matters when we measure temporality and its concentration. Shopping has a high concentration on sequences with transport (of any kind) preceding nearly half and following a third of shopping episodes. It also has the lowest concentration on tempo: over the week $10 \%$ of the episodes last 10 minutes or less, $10 \%$ last more than an hour and a half. On Saturdays (appendix table A2), its periodicity, synchronisation and duration are different than on Mondays: on Saturdays, people do shopping more often, for a longer time and at different hours than Mondays. Their shopping is also more concentrated, hence shared in more similar ways, on Saturdays. This points to the fact that shopping has a weekly rather than a daily time-frame. 
Table 2: Position and concentration rank of food-related practices on five dimensions of temporality, Dutch time-use survey 2011

\begin{tabular}{|c|c|c|c|c|c|c|c|c|c|c|c|}
\hline \multirow[b]{2}{*}{ Dimension } & \multirow[b]{2}{*}{ Definition of position } & \multicolumn{2}{|c|}{ Cooking } & \multicolumn{2}{|c|}{ Cleaning* } & \multicolumn{2}{|c|}{ Meal } & \multicolumn{2}{|c|}{ Shopping } & \multicolumn{2}{|c|}{ Snack } \\
\hline & & Position & $\begin{array}{c}\text { Concentration } \\
\text { rank }\end{array}$ & Position & $\begin{array}{c}\text { Concentration } \\
\text { rank }\end{array}$ & Position & $\begin{array}{c}\text { Concentration } \\
\text { rank }\end{array}$ & Position & $\begin{array}{c}\text { Concentration } \\
\text { rank }\end{array}$ & Position & $\begin{array}{c}\text { Concentration } \\
\text { rank }\end{array}$ \\
\hline Periodicity & $\begin{array}{l}\text { Mean number of episodes per } \\
\text { day (Monday) }\end{array}$ & 1.11 & 2 & 0.72 & 3 & 2.39 & 1 & 0.34 & 4 & 0.08 & 5 \\
\hline Synchronisation & $\begin{array}{l}\text { Modal hour of participation } \\
\text { (Monday) }\end{array}$ & $17: 20$ & 2 & $18: 40$ & 3 & $18: 10$ & 1 & $13: 50$ & 4 & $15: 30$ & 5 \\
\hline Duration & $\begin{array}{l}\text { Mean of total time for } \\
\text { participant (Monday) }\end{array}$ & $0: 43$ & 2 & $0: 28$ & 4 & $1: 13$ & 1 & $0: 48$ & 5 & $0: 20$ & 3 \\
\hline Tempo & Median episode duration & 20 & 4 & 10 & 1 & 30 & 4 & 40 & 5 & 10 & 2 \\
\hline \multirow[t]{2}{*}{ Sequence } & Most frequent activity before & Wash/dress & 4 & Meal & 1 & Cooking & 3 & Transport & 2 & Watch TV & 5 \\
\hline & Most frequent activity after & Meal & 1 & Meal & 4 & Cleaning & 3 & Transport & 2 & Watch TV & 5 \\
\hline \multicolumn{2}{|c|}{ \# of dimensions with highest concentration (C1) } & & 1 & & 2 & & 3 & & 0 & & 0 \\
\hline \multicolumn{2}{|c|}{$\#$ of dimensions with lowest concentration (C5) } & & 0 & & 0 & & 0 & & 2 & & 3 \\
\hline \multicolumn{2}{|c|}{ Concentration index (difference $\mathrm{C} 1-\mathrm{C} 5$ ) } & & 1 & & 2 & & 3 & & -2 & & -3 \\
\hline
\end{tabular}

Concentration rank from highest (1) to lowest (5)

* Cleaning includes setting the table, clearing the table, doing the dishes, fill or empty the dishwasher.

Source: Dutch time-use survey 2011 (Centraal Bureau voor de Statistiek, 2012b), full sample ( $=2005)$.

Note: The full results appear in the appendix - definition of the indicators (Table A1), value of the concentration parameters and results for Saturdays (Table A2). 


\section{Discussion: Characterising the sharedness of practices}

This study interrogated the relationship of praxeological thinking and time-use analysis. We offer empirical clues to assess how and to what extent a given practice is shared. Practice approaches deploy conceptual tools to investigate food consumption as a process that unfolds in time. Using the praxeological literature we emphasised participation, commitment and concentration as characteristics of sharedness. We applied this characterisation to five practices involved in food consumption, in the Dutch time-use survey collected in 2011-2012. We would like to discuss the results based on a summary in Figure 2 below. It maps the three characteristics of sharedness, based on our analysis of the Dutch time-use data. The vertical axis represents participation and the horizontal concentration. The diameter of the disks is proportional to commitment measured by total time per week among participants. Figure 1: Participation, commitment and temporal concentration for food consumption
practices

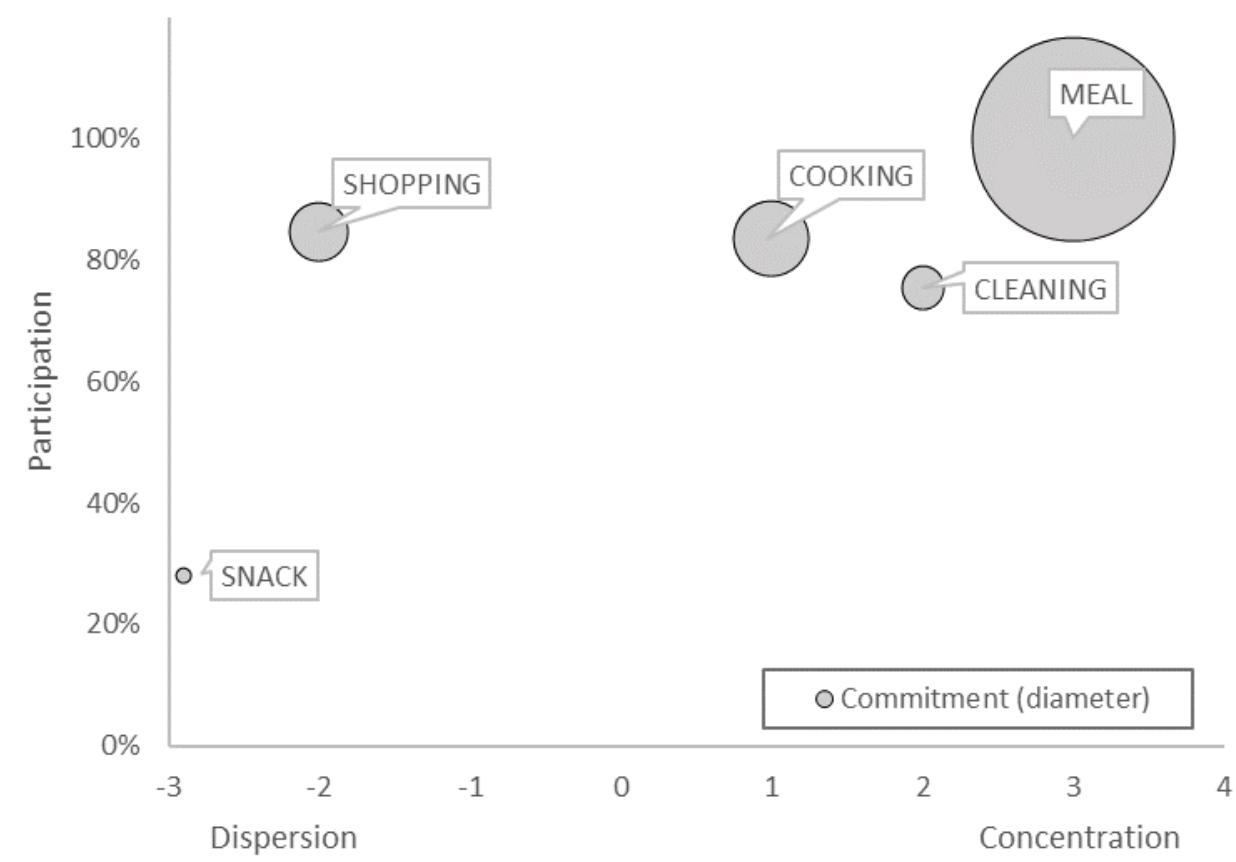

Participation: \% participating at least once over the survey week.

Commitment: diameter of the circle is proportional to the total time over the week.

Concentration: concentration index computed in Table 2.

Source: Dutch Time use survey 2011 (Centraal Bureau voor de Statistiek, 2012b), full sample $(\mathrm{N}=2005)$.

The five food-related practices form three clusters. First, the practices of eating a meal, cleaning and cooking score high both on participation and temporal concentration. For example, most Dutch ate three meals a day (participation), around 7:00,12:30 and 18:10 (concentration). The dimension of sequences 
indicates that the three practices are strongly coordinated, since they follow each other often ${ }^{\text {iii }}$. Commitment as measured by total time per week among participants, varies from very high for the meal, to average for cooking and rather low for cleaning. Had we graphed the number of episodes per week, eating a meal, cooking and cleaning would have had the three highest degrees of commitment (in that order). These activities (and the meal in particular) are shared in every sense of the word.

The second cluster, opposite to the meal, is formed by snacking. It scores lowest on all three characteristics of sharedness. On the sequence dimension, unsurprisingly, we found that it was very dispersed, with the most frequent activity before or after representing only $10 \%$ of the episodes. It did not form sequences with other food-related practices, but with watching television (the next most frequent activities before or after snacking were paid work and attending class). Dispersed, rare, short and isolated from other food practices, snacking therefore appears as the exact opposite of the first cluster, and strongly contrasts with eating a meal. The third and last cluster is comprised of shopping, located in the upper left corner of figure 1: It is characterised by high participation, medium commitment, but low concentration. Our results suggest that the temporality of shopping is a little more complicated: thanks to the weekly data set, we are able to detect that on Saturdays it has a higher degree of commitment and concentration than on other days. Shopping illustrates an activity that is widely shared, but on a less frequent basis than the meal. As regards sequences, shopping could be compared to snacking because it follows or precedes transport of any kind. But contrary to snacking, shopping shows a high concentration on the dimension of sequence, with transport preceding nearly half and following a third of shopping episodes. This makes shopping the second most concentrated practice on the dimension of sequence, while snacking was the last. This means that shopping is more embedded in the same practices (transport) than snacking. Additionally, when examining the next most frequent sequences involving shopping, food consumption practices come up: meals follow or precede $7.5 \%$ of shopping episodes. Cooking and drinking follow $7 \%$ and $4.3 \%$ of shopping episodes respectively.

The lower right corner of our diagram is empty. It could host practices that are exclusive, that is, whose practitioners are few but perform in very specific ways, resulting in high temporal concentration. While we haven't included such practices in this study, we can find examples in sociological research, such as dining in a restaurant (Paddock et al., 2017), or taking medication for chronic illness (McCoy, 2009). Our empirical analysis of sharedness allows us to reflect on culture and power in theorizing social practices. First, when it comes to food cultures, it is commonplace to argue that ritualised food practices, in terms of content and temporalities, contribute to reinforcing cultural belonging and collective identities (Shove et al., 2012; Zerubavel, 1976). It is quite reasonable to assume that the more a practice is shared, i.e., the higher its participation, commitment and temporal concentration in a given society or cultural group, the more it contributes to this group's identity. In this sense, meals would strongly contribute to several Western identities because nearly everyone participates, with a high degree of commitment and in specific ways, temporally speaking. Snacks may be less culturally significant in the 
Netherlands, except maybe in contrast with societies (or times) where snacks show a strong participation, commitment or temporal concentration. Participation, commitment and temporal concentration of sharedness objectify cultural changes in everyday life. Time-use data allows to account for cultural changes and differences in practices, because these data are available for different localities and times. In addition, the sample size in time-use surveys allows examining whether such changes are widespread or specific to a category of population (Gershuny, 2000; Sullivan and Gershuny, 2001). While we have not done so here for lack of space, time-use data and a praxeological perspective may assist in accounting for inequalities in social practices.

The second aspect of shared practices we want to reflect upon is power. Shove and colleagues (2012), citing Pred (1981), consider that some practices take ‘time precedence' over others, and succeed better at capturing our time. Pred shows that such practices become unavoidable on our daily path, as part of our social role - a parent is supposed to drop the kids to school every morning, a kid is supposed to be in school every school-day according to a specific schedule. Such practices are 'dominant projects' for these social roles. From this perspective, it would be legitimate to speak of 'the power of a practice' as the extent to which people feel that they have no other choice than to perform the practice, at specific times of the day or week or in a specific sequence. Similarly, in his chapter on collective action, Barnes (2001) argued that shared practices had power: the more coordinated, the more power they had. The cavalry has power in the battlefield: even if it does not move, both camps anticipate that it might charge and take this into consideration when fighting. The better the cavalry is capable of performing a coordinated charge, the stronger its power. Similarly, our analysis suggests that the power of the meal lies in its coordination, which produces its high temporal concentration: because the Dutch tend to eat at the same hour (and for similar duration etc.) other practices get moulded around it-leisure activities, movies and TV time schedules and even, to some points, parents' working schedules and careers. Additionally, the meal is embedded in the same practices, whereas snacking is not. Cooking is less dominant, i.e. has less power, because more people can allow themselves to skip it (or delegate it). If ever more people can free themselves of the commitment to and temporal organisation of cooking, then the practice is probably losing power. Time-use surveys allow measuring such changes in social practices (Plessz and Étilé, 2019). Conversely, our praxeological framework makes it possible to discuss such issues as culture and power with time-use surveys.

\section{Conclusion}

Our investigation expands examples of and arguments for deploying TUSs, and quantitative data in general, for praxeological analysis. We provided theoretical and empirical insight on the sharedness of practices. TUSs have been replicated in many countries for decades, hence allow to analyse long-term changes or country differences in everyday practices (Cheng et al., 2007; Gershuny and Harms, 2016; Plessz and Étilé, 2019). Practice theories could make use of such longitudinal evidence. We add to a 
number of sociological papers (Cheng et al., 2007; Daniels et al., 2012; Saint Pol (de), 2006; Southerton et al., 2012; Warde and Yates, 2017) moving beyond the analysis of large activity categories, whose sociological relevance is sometimes taken for granted but can be questioned. From a praxeological perspective, the category of unpaid work - a potluck containing cleaning the car, sewing and cookingdoes not make much sense. Through notions such as shared understandings and modes of engagements, theories of practice can help time-use survey analysts to account for why people consider that they must take the time to clean the table, but 'don't have the time' to cook. Time-use surveys in turn supplies empirical and methodological tools to practice theories, in order to compare practices to each other, or across time and place. While measuring practices' characteristics is not always necessary, it is central when one wants to address classical sociological questions such as inequalities, social change, or cultural differences.

TUSs investigate practices as performances, disregarding the practice's entity, understandings, or engagements (although see Daniels et al, 2012). Despite that, we were able to describe how exactly food consumption practices are 'shared'. Such an approach assists in overcoming some often-reported shortcomings of theories of practice, specifically the lack of methodological guidance, and the inability to address power relationships. We empirically substantiated Welch and Yates's (2018) intuition that temporal concentration indicates that practices are collective even when performed by dispersed individuals such as randomly sampled survey respondents. This only required basic descriptive statistics - means, coefficients of variation, percentages - that could easily be replicated on other timeuse surveys or for other practices. We also discussed how sharedness and temporal concentration relate to the power of practices. Powerful practices might be seen as those that capture our time, organising the temporality of other practices, hence of our lives, around them (Pred 1981). This eventually opens perspectives for addressing power relations between groups of practitioners, such as class, race or gender relations, in a praxeological perspective: one might compare how shared and concentrated cooking is, in men's and women's days. In some countries, TUSs even allow to compare partners' schedules.

This paper did not investigate the processes and actors that coordinate the practices and generate their temporal concentration (and possibly their power). We do not address coordination, since we did not examine people actually sharing the practice (eating together, cooking for the household) nor institutions organising it. This would require other investigations in various areas (school, business and leisure hours, education and socialisation, family interactions etc). But no matter how coordination is achieved, it produces temporal concentration, which probably reinforces itself by forcing actors and practices to align on others' temporalities. While this paper only dealt with five practices related to food consumption, it revealed the intricacies of sharedness in practices. The three characteristics of sharedness might play a key role in identifying the temporal organisation of daily life, not aggregating major categories such as labour or leisure, but engaging in meaningful analysis of the interplay between practices as performances and as entities. This opens up possibilities to identify dispersed collective 
activity, and to advance the relevance of practice theories for broader sociological questions relating to power relations, lifestyle differences, and collective identities.

\section{References}

Abbott A (2001) Time Matters. Chicago: University of Chicago Press.

Anderson B (2016) Laundry, energy and time: Insights from 20 years of time-use diary data in the United Kingdom. Energy Research \& Social Science 22: 125-136. DOI: 10.1016/j.erss.2016.09.004.

Barnes, B. (2001) Practices as collective action. In: Theodore Schatzki, Karin Knorr-Cetina and Eike von Savigny (eds.): The practice turn in contemporary theory. London: Routledge.

Blue, S (2017) Institutional rhythms: Combining practice theory and rhythmanalysis to conceptualise processes of institutionalisation. Time \& Society. DOI:10.1177\%2F0961463X17702165

Brannen J, O'Connell R and Mooney A (2013) Families, meals and synchronicity: eating together in British dual earner families. Community, Work \& Family 16(4): 417-434. DOI: 10.1080/13668803.2013.776514.

Callejo J and Díaz-Méndez C (2014) Homogenization of eating times in the United Kingdom and Spain. British Food Journal 116(5): 734-752. DOI: 10.1108/BFJ-05-2012-0121.

Centraal Bureau voor de Statistiek (2012a) TBO 2011-2012 Codelijst met toelichting [TUS 2011-2012 Codelist with explanations]. Centraal Bureau voor de Statistiek. Available at: https://www.scp.nl/dsresource?objectid=758e61a1-46ae-46be-b13a-b4d2862c20ad (accessed 23 July 2018).

Centraal Bureau voor de Statistiek (2012b) Tijdsbestedingsonderzoek 2011/2012 Onderzoeksdocumentatie [Time use survey 2011-2012: survey documentation]. Centraal Bureau voor de Statistiek. Available at: https://www.scp.nl/dsresource?objectid=2408137b-dcea-4e87b4df-aae212f64016\&type $=$ org (accessed 23 July 2018).

Cheng S-L, Olsen W, Southerton D, et al. (2007) The changing practice of eating: evidence from UK time diaries, 1975 and 2000. The British Journal of Sociology 58(1): 39-61. DOI: 10.1111/j.14684446.2007.00138.x.

Cloïn M (2012) A day with the Dutch: time use in the Netherlands compared with 15 other European countries. The Hague: Netherlands Inst. for Social Research.

Daniels S, Glorieux I, Minnen J, et al. (2012) More than preparing a meal? Concerning the meanings of home cooking. Appetite 58(3): 1050-1056. DOI: 10.1016/j.appet.2012.02.040.

Fine GA (1996) Kitchens : the culture of restaurant work. Berkeley: University of California Press.

Gershuny J (2000) Changing times: works and leisure in postindustrial society. Oxford: Oxford University Press.

Gershuny J and Harms TA (2016) Housework Now Takes Much Less Time: 85 Years of US Rural Women's Time Use. Social Forces 95(2): 503-524. DOI: 10.1093/sf/sow073.

Holm L, Lauridsen D, Lund TB, et al. (2016) Changes in the social context and conduct of eating in four Nordic countries between 1997 and 2012. Appetite 103: 358-368. DOI: 10.1016/j.appet.2016.04.034.

Holmes H (2015) Self-time: The importance of temporal experience within practice. Time \& Society. DOI: $10.1177 / 0961463 X 15596461$.

Lhuissier A, Tichit C, Caillavet F, et al. (2013) Who still eats three meals a day? Findings from a quantitative survey in the Paris area. Appetite 63(0): 59-69. DOI: 10.1016/j.appet.2012.12.012. 
Mylan J, Southerton D (2018) The Social Ordering of an Everyday Practice: The Case of Laundry. Sociology. 52 (6): 1134-1151. DOI:10.1177\%2F0038038517722932

McCoy L (2009) Time, self and the medication day: a closer look at the everyday work of 'adherence'. Sociology of Health \& Illness 31(1): 128-46. DOI: 10.1111/j.1467-9566.2008.01120.x.

Paddock J, Warde A and Whillans J (2017) The changing meaning of eating out in three English cities 1995-2015. Appetite 119: 5-13. DOI: 10.1016/j.appet.2017.01.030.

Plessz M and Étilé F (2019) Is cooking still a part of our eating practices? Analysing the decline of a practice with time-use surveys. Cultural Sociology DOI: 10.1177\%2F1749975518791431.

Plessz M and Gojard S (2015) Fresh is Best? Social Position, Cooking, and Vegetable Consumption in France. Sociology 49(1): 172-190. DOI: 10.1177/0038038514521715.

Pred A (1981) Social Reproduction and the Time-Geography of Everyday Life. Geografiska Annaler. Series B, Human Geography 63(1): 5-22. DOI: 10.2307/490994.

Saint Pol (de) T and Ricroch L (2012) Le temps de l'alimentation en France. INSEE Première (1417): $1-4$.

Saint Pol (de) T (2005) Quand est-ce qu'on mange ? Le temps des repas en France (analyse quantitative). Terrains et travaux 2(9): 51-72.

Schatzki TR (1996) Social Practices-A Wittgensteinian Approach to Human Activity and the Social. Cambridge: Cambridge University Press.

Schatzki TR (2001) Introduction: Practice theory. In: Schatzki TR, Knorr Cetina K, and Savigny E von (eds) The Practice Turn in Contemporary Theory. New York: Routledge, pp. 10-23.

Shove E, Trentmann F and Wilk RR (eds) (2009) Time, consumption and everyday life: practice, materiality and culture. Oxford: Berg.

Shove E, Pantzar M and Watson M (2012) The dynamics of social practice: everyday life and how it changes. Los Angeles: SAGE.

Southerton D (2006) Analysing the Temporal Organization of Daily Life: Social Constraints, Practices and their Allocation. Sociology 40(3): 435-454. DOI: 10.1177/0038038506063668.

Southerton D (2013) Habits, routines and temporalities of consumption: From individual behaviours to the reproduction of everyday practices. Time \& Society 22(3): 335-355. DOI: $10.1177 / 0961463 X 12464228$.

Southerton D, Olsen W, Warde A, \& Cheng, S (2012) Practices and trajectories: a comparative analysis of reading in France, Norway, the Netherlands, the UK and the U.S.A. Journal of Consumer Culture 12(3): 237-262. DOI: 10.1177/1469540512456920.

Southerton D (2003) 'Squeezing Time': Allocating Practices, Coordinating Networks and Scheduling Society. Time \& Society 12(1): 5-25. DOI: 10.1177/0961463X03012001001.

Sullivan O (2000) The Division of Domestic Labour: Twenty Years of Change? Sociology 34(3): $437-$ 456. DOI: $10.1177 / \mathrm{s} 0038038500000286$.

Tai T and Treas J (2013) Housework Task Hierarchies in 32 Countries. European Sociological Review 29(4): 780-791. DOI: $10.1093 / \mathrm{esr} / \mathrm{jcs} 057$.

Tienoven TP van, Glorieux I, Laurijssen I, et al. (2011) The Social Structure of Time: Optimal Matching for Time-Use Data. Unpublished. DOI: 10.13140/2.1.3826.2565.

Tienoven TP van, Glorieux I and Minnen J (2017) Exploring the stable practices of everyday life: A multi-day time-diary approach. The Sociological Review: 003802611667488. DOI: $10.1177 / 0038026116674886$.

Tienoven TP van (2018): A multitude of natural, social and individual time. Time \& Society. DOI:10.1177/0961463X17752554. 
Truninger M (2011) Cooking with Bimby in a moment of recruitment: Exploring conventions and practice perspectives. Journal of Consumer Culture 11(1): 37-59.

Twine R (2015) Understanding snacking through a practice theory lens. Sociology of Health \& Illness 37(8): 1270-1284. DOI: 10.1111/1467-9566.12310.

Warde A (2005) Consumption and theories of practice. Journal of Consumer Culture 5(2): 131-153. DOI: $10.1177 / 1469540505053090$.

Warde A (2013) What sort of practice is eating? In: Shove E and Spurling N (eds) Sustainable Practice: social theory and climate change. Londres: Routledge, pp. 17-30.

Warde A (2016) The practice of eating. London: Polity Press.

Warde A and Yates L (2017) Understanding Eating Events: Snacks and Meal Patterns in Great Britain. Food, Culture \& Society 20(1): 15-36. DOI: 10.1080/15528014.2016.1243763.

Welch D and Yates L (2018) The practices of collective action: Practice theory, sustainability transitions and social change. Journal for the Theory of Social Behaviour. 48 (3): 288-305. DOI: $10.1111 /$ jtsb. 12168 .

Yates L and Warde A (2017) Eating together and eating alone: meal arrangements in British households. The British Journal of Sociology 68(1): 97-118. DOI: 10.1111/1468-4446.12231.

Zerubavel E (1979) Patterns of Time in Hospital Life: A Sociological Perspective. Chicago: University of Chicago Press. 


\section{Appendix}

Table A1: Measuring time dimensions and their concentrations in Time-use surveys

\begin{tabular}{|c|c|c|c|c|}
\hline $\begin{array}{l}\text { Temporal } \\
\text { Dimension }\end{array}$ & Measurement & Position parameter & $\begin{array}{l}\text { Dispersion/concentration } \\
\text { parameter }\end{array}$ & $\begin{array}{l}\text { Highest } \\
\text { concentration }\end{array}$ \\
\hline Periodicity & Number of episodes per day & Mean & Dispersion: Coefficient of variation ${ }^{a}$ & Lowest value \\
\hline $\begin{array}{l}\text { Synchronis- } \\
\text { ation }\end{array}$ & $\begin{array}{l}\text { Clock-time of the day (starting } \\
\text { time of the 10-minute slot) }\end{array}$ & $\begin{array}{l}\text { Mode (time-slot with } \\
\text { max participation) }\end{array}$ & $\begin{array}{l}\text { Concentration: relative participation } \\
\text { for this time-slot }{ }^{\mathrm{b}}\end{array}$ & Highest value \\
\hline Duration & $\begin{array}{l}\text { Total duration per day among } \\
\text { participants }\end{array}$ & Mean & Dispersion: Coefficient of variation & Lowest value \\
\hline Tempo & Episode duration (minutes) & Median & Dispersion: Range D1 D9c & Widest range \\
\hline Sequence & $\begin{array}{l}\text { Activities following/preceding } \\
\text { an episode of each food-related }\end{array}$ & Most frequent activity & $\begin{array}{l}\text { Concentration: \% episodes } \\
\text { following/preceded by this activity }\end{array}$ & Highest value \\
\hline
\end{tabular}

${ }^{a}$ Coefficient of variation: standard deviation divided by the mean. A coefficient of variation is a standardized measure of dispersion. When it is below 1 the variance is considered low or, the concentration around the position parameter (mean, mode or median) is high.

${ }^{\mathrm{b}}$ Relative participation: participation rate at that time, among those who had participated at least once on the day considered .

${ }^{\mathrm{c}}$ Limits of the first and ninth decile (an interval including $80 \%$ of the observations). 
Table A2: Position and dispersion of food-related practices on five dimensions of temporality, Dutch time-use survey 2011

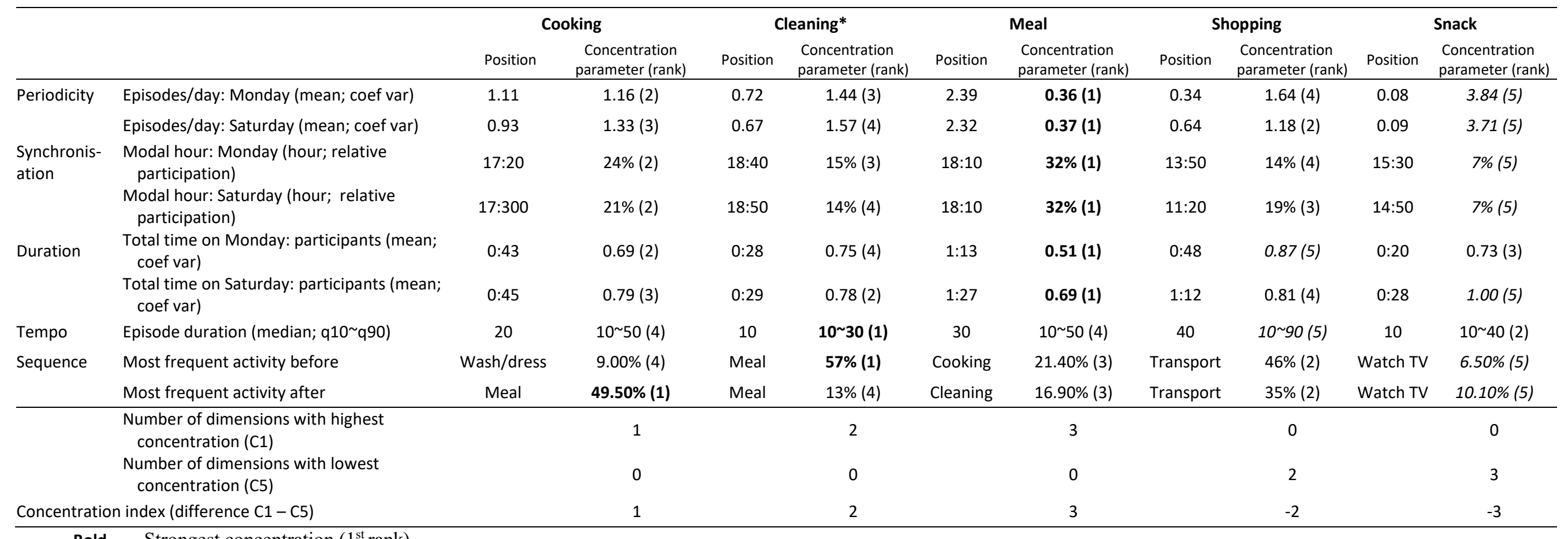

Bold Strongest concentration ( $1^{\text {st }}$ rank)

Italics Lowest concentration $\left(5^{\text {th }}\right.$ rank)

* Cleaning includes setting the table, clearing the table, doing the dishes, fill or empty the dishwasher.

Source: Dutch time-use survey 2011 (Centraal Bureau voor de Statistiek, 2012b), full sample (N = 2005).

Reading note: As regards periodicity, cooking is performed 1.11 times on Mondays, with a coefficient of variation of 1.16 (the second strongest concentration). As regards synchronisation, the hour of maximum participation is 17:20 with $24 \%$ of the respondents cooking at that time. As regards duration, people who have cooked at least once on a Monday have done so for 43 minutes, with a low coefficient of variation (0.69). Half of the cooking episodes lasted less than 21 minutes, with $90 \%$ lasting between 10 and 50 minutes. The most frequent activities performed before and after cooking are washing/dressing and eating a meal, with $9 \%$ and $49.5 \%$ of respondents declaring these activities, respectively. 


\section{Notes}

i We focus on practices as performances, leaving aside the question of how the 'practice as entity' is shared. While
both aspects are obviously connected (Mylan and Southerton, 2018), dealing with both would exceed the space of
this paper and this choice is consistent with the choice of a time-use survey as empirical material.
ii More and more researchers use sequence analysis (or optimal matching). It identifies similar sequences of
activities in diaries and generates typologies. We decided not to do it because it did not fit our research goals and
its technical requirements impose limitations to the analyses, that we were not ready to accept (Tienoven et al,
$2011: 150)$.
iii One might wonder why every cooking episode is not followed by eating a meal. The reason is we are only
examining the activity reported just after cooking. Other activities may be performed between cooking and eating.
the activities most often reported after cooking are: eating a meal (49\%), drinking ( $9 \%$ ), cleaning (which includes
setting the table, $4 \%$ ) and watch TV (4\%). Note that eating a snack is not in this list, strongly contrasting with
eating a meal. 